\title{
A CONCEPÇÃO BURGUESA DE EDUCAÇÃO TECNOLÓGICA E DE DESENVOLVIMENTO ECONÔMICO E A POLÍTICA DE CIÊNCIA, TECNOLOGIA E INOVAÇÃO NO BRASIL
}

\author{
THE BOURGEOIS CONCEPTION OF TECHNOLOGICAL EDUCATION AND \\ ECONOMIC DEVELOPMENT AND THE SCIENCE, TECHNOLOGY AND \\ INNOVATION POLICY IN BRAZIL
}

\begin{abstract}
LA CONCEPCIÓN BURGUESA DE LA EDUCACIÓN TECNOLÓGICA Y DEL DESARROLLO ECONÓMICO Y LA POLÍTICA DE CIENCIA, TECNOLOGÍA E INNOVACIÓN EN BRASIL
\end{abstract}

Zuleide S. Silveira

(UFF, Brasil)

do) https://doi.org/10.29404/rtps-v5i8.393

RESUMO: 0 artigo analisa o desenvolvimento da concepção burguesa de educação tecnológica no bojo do processo de institucionalização e implementação da política de ciência e tecnologia, mais tarde denominada política de ciência, tecnologia e inovação (CT\&I), evidenciando o movimento de subsunção da política educacional à política de CT\&I no período de 1960 a 1990. A partir do reexame da teoria do capital humano, busca-se evidenciar a gênese da subsunção da política educacional à política de CT\&I para desvelar a concepção e abrangência da educação tecnológica na perspectiva burguesa. À guisa de conclusão, é apontada a mudança de paradigma da produção do conhecimento para um caráter cooperativo de produção e reprodução do capital. Isto exige a formação de diferentes capacidades de trabalho sob a envergadura da educação tecnológica.

Palavras-Chave: Educação Tecnológica, Desenvolvimento Econômico, Política de Ciência e Tecnológica, Pesquisa e Desenvolvimento, Adaptação à Inovação Tecnológica.

\begin{abstract}
The article analyzes the development of the bourgeois conception of technological education within the process of institutionalizing and implementing the science and technology policy, later called the science, technology and innovation policy (ST\&I), highlighting the movement from the subsumption of educational policy to politics of ST\&I in the period from 1960 s to 1990s. Based on the reexamination of the theory of human capital, it seeks to highlight the genesis of the subsumption of educational policy to the ST\&I policy to unveil the conception and scope of technological education in the bourgeois perspective. In conclusion, the paradigm shift from knowledge production to a cooperative character of capital production and reproduction is pointed out. This requires the formation of different work capacities under the scope of technological education.
\end{abstract}

Keywords: Technological Education, Economic Development, Science and Technological Policy, Research and Development, Adaptation to Technological Innovation.
RESUMEN: El artículo analiza el desarrollo de la concepción burguesa de la educación tecnológica en medio del proceso de institucionalización e implementación de la política científica y tecnológica, más tarde llamada política de ciencia, tecnología e innovación (CT\&l), destacando el movimiento de la política educativa a la política. de CT\&I en el período de 1960 a 1990. Desde el reexamen de la teoría del capital humano, buscamos resaltar la génesis de la subsunción de la política educativa a la política de CT\&I para revelar la concepción y el alcance de la educación tecnológica en la perspectiva burguesa. En conclusión, se señala el cambio de paradigma de la producción de conocimiento a un carácter cooperativo de producción y reproducción de capital. Esto requiere la formación de diferentes capacidades de trabajo en el ámbito de la educación tecnológica.

Palabras Clave: Educación Tecnológica, Desarrollo Económico, Ciencia y Política Tecnológica, Investigación y Desarrollo, Adaptación a la Innovación Tecnológica. 


\section{Introdução}

Logo após a Segunda Guerra Mundial, inicia-se o processo de institucionalização da política de Ciência e Tecnologia (C\&T), cujas bases conceituais, estrutura organizacional, instrumentos de financiamento e formas de avaliação são, até hoje, comuns aos países que desenharam e implementaram políticas explícitas para estimular a produção e utilização de conhecimento científico-tecnológico voltado para o crescimento econômico (VELHO, 2006). Tal contexto caracteriza-se pela conversão da pesquisa e, por conseguinte, da produção do conhecimento, em atividade sistemática com o fito de responder ao processo de internacionalização da economia e de sua correlata, a internacionalização da tecnologia.

Dos Santos (1994) observa que tal conversão associada ao mercado mundial deu origem a novos setores de produção e serviços, como a energia nuclear, a petroquímica, a informática, a indústria espacial, ramos do conhecimento que, até então, não se voltavam imediatamente à acumulação capitalista. Criou-se, em consequência, uma vasta população de cientistas, tecnólogos e funcionários auxiliares que se associaram a um vasto grupo de instituições dedicadas à Pesquisa e Desenvolvimento (P\&D) e à formação de pessoal qualificado para este fim.

Como o capital em concorrência executa sua tendência imanente à produção de conhecimento, sobretudo o inovador (CIPOLLA, 2006), foram criados institutos e centros de pesquisa aplicada, laboratórios de P\&D e, com eles, os ministérios e as secretarias de Estado, que passaram a envolver lenta e gradualmente as instituições de ensino em um movimento que já trazia em seu bojo o desenvolvimento da concepção burguesa de educação tecnológica e a relação Estado, universidade e empresa (estatal e privada).

No Brasil, este movimento tem sua gênese, em 1964, no Fundo Tecnológico (FUNTEC) e culmina na criação do Sistema Nacional de Ciência, Tecnologia e Inovação (SNCTI), nos anos de 1985-2001, cujo arcabouço legislativo consolida a subsunção da política educacional à política de C\&T. Esta, por sua vez, responde à dinâmica da internacionalização da economia/tecnologia. Não sem razão, no Brasil contemporâneo, o Marco Legal de Ciência, Tecnologia e Inovação, Lei no 13.243/2016 - regulamentado pelo Decreto $n^{\circ}$ 9.283/2018 -, veio aprofundar o processo de privatização da universidade e do patrimônio científico-tecnológico já iniciado pela Lei de Inovação, Lei n 10.973/2004 (BRASIL, 2004; 2016; 2018).

Todavia, no século XIX, Marx e Engels demarcaram uma concepção de educação tecnológica totalmente diferenciada da atual. No início do século XX, ela foi traduzida pelos educadores da Revolução de 1917 como politecnia, mas também foi a base da proposta de escola única, de Gramsci, nos Cadernos do Cárcere. Tal concepção revolucionária toma o trabalho como princípio educativo, busca a unidade educação e produção material, em cuja essência encontra-se a unidade teoria e práxis. Seu caráter de totalidade ou omnilateralidade do homem está na possibilidade de sua emancipação e realização plena 
de si mesmo, independente das ocupações específicas de um determinado posto de trabalho.

Nas experiências revolucionárias, Viktor Shulgin ${ }^{1}$ avança na discussão dos conceitos de trabalho socialmente necessário e propõe um sistema de ensino, o qual denomina de politecnismo, que inicia na educação infantil e segue até umbrais da educação superior. Trata-se de uma contribuição importante na medida em que se alude à politecnia somente quando se trata do nível médio de ensino e, mesmo assim, em sua conexão com o trabalho produtivo (FREITAS, 2013).

Atualmente, a educação tecnológica abarca a totalidade do sistema nacional de ensino, mas como veremos, na perspectiva da máquina produtiva capitalista.

\section{Pensamento econômico e educação: um reexame da Teoria do Capital Humano}

Com o desenvolvimento periódico das forças produtivas, a divisão internacional do trabalho assume diferentes configurações articulada à dinâmica expansionista do capital, em nível internacional. Finda a Segunda Guerra Mundial, tal dinâmica passa a requerer estabilidade e previsibilidade institucional, econômica e societária (DREIFUSS, 1986, 2004 MÉSZÁROS, 2006). Por mediação de chefes, ministros e secretários de Estado, empresários, homens e mulheres de negócio e, de modo geral, tecnocratas ${ }^{2}$, as burguesias, local e internacional, sob a hegemonia do E.U.A., passam a requerer o planejamento integrado e coordenado das políticas econômica, educacional e científico-tecnológica como resposta às necessidades de crescimento econômico, modernização e à solução para os problemas sociais.

No plano educacional, desencadeia-se, em diferentes países, a pedagogia oficial de cunho tecnocrático, baseada nos princípios da racionalidade, eficiência e produtividade, como resposta às severas críticas desferidas contra os modelos humboldtiano e napoleônico de universidade e, de modo geral, à escola, tidas como arcaicas, desinteressantes, desatualizadas, reprodutivistas das desigualdades sociais e, por

\footnotetext{
1 Viktor Shulgin Nikcholaevich Shulgin (1896-1965), educador e historiador dentre outras atribuições no período da Revolução Russa, trabalhou no Comissariado do povo para a Educação (1918-1922) e trabalho junto a Moyses Pistrak na Escola-Comuna Experimental Demonstrativa do referido Comissariado em Moscou. Da empiria extraiu conceitos e categorias analíticas de relevância e atualidade como, auto-organização, atualidade, e trabalho socialmente necessário na escola.

2 Entendemos, com Ianni (1996, p. 315), que a noção de tecnocracia envolve, fundamentalmente, um conjunto de intelectuais (economistas, engenheiros, agrônomos, geólogos, urbanistas arquitetos, educadores, projetista, etc.) que exercem as principais atividades no processo de elaboração, execução e controle das políticas públicas, dando-lhes um caráter eminentemente técnico.
} 
conseguinte, responsáveis pelo atraso do setor produtivo e do desenvolvimento econômico do Estado-Nação.

Na dimensão econômica, marcada pelas teorias dualistas e pela euforia em torno da qual a dinâmica das economias de mercado funciona de modo socialmente progressivo e convergente, as concepções conservadoras do "bem-estar" preparam o terreno éticopolítico e teórico que se repercute até hoje com base na teoria da justiça, de John Rawls, e na teoria do capital humano3 ${ }^{3}$ (MEDEIROS, 2013, p. 262-299).

Pobreza, desigualdade social e outras mazelas da sociedade passam a ser vistas como manifestações do atraso, do arcaico e do subdesenvolvido, engendradas pelo baixo nível de escolarização da população e inexistência de pessoal qualificado nas diferentes áreas do conhecimento. Desconsidera-se, por conseguinte, o desenvolvimento sócio-histórico e cultural de diferentes países, suas opções político-econômica e socioeducacional, os monopólios, as lutas de classe e as forças produtivas locais.

Ao contrário da teoria da justiça que, ao criticar a filosofia utilitarista, funciona como uma inflexão na linha evolutiva do pensamento econômico, a TCH pode ser vista, segundo Medeiros (2013), como o epílogo do longo desdobramento da obra de Jeremy Bentham (1789). Ela se traduz em um programa de pesquisa científica apoiado na Economia, Sociologia, Antropologia, Educação, entre outros ramos do saber,

orientado a explicar ou prever relações factuais tão distintas quanto a que supostamente existiria entre o processo de universalização da educação formal e o crescimento econômico (relação esta concernente à Macroeconomia) e a regularidade empírica existente entre os diferenciais de educação e renda pessoal (assuntos típicos das teorias do "bem-estar" social) (MEDEIROS, 2013, p. 285).

Nesta perspectiva, o capital humano é visto como um valor que reúne a saúde física e mental, talentos individuais inatos, habilidades e competências adquiridas pela educação formal e não-formal, bem como a capacitação em serviço.

\footnotetext{
Human capital analysis starts with the assumption that individuals decide on their education, training, medical care, and other additions to knowledge and health by weighing the benefits and costs. Benefits include cultural and other non-monetary gains along with improvement in earnings and occupations, while costs usually depend mainly on the foregone value of the time spent on these investments (BECKER, 1992, p. 43).
}

Além de fator econômico, a educação mantém-se incorporada à dimensão social do Estado-Nação e, mais recentemente, do bloco político-econômico regional a que se vincula, porque transmite valores como a empatia, a igualdade de oportunidades, produz

\footnotetext{
${ }^{3}$ Doravante TCH.
} 
efeitos positivos na qualidade de vida, no combate ao crime e, ainda, contribui para a redução dos conflitos sociais entre e intraclasses sociais ${ }^{4}$.

Ainda que a abordagem do conceito de capital humano surgisse fragmentada nos manuscritos dos economistas, desde os clássicos aos neoclássicos, o que suscitou um conjunto de pesquisas, nos anos 1950-1960, em torno da temática economia e educação foi a constatação empírica de que, tanto nos E.U.A. quanto na Europa ocidental da aplicação do Plano Marshall, havia um crescimento econômico fantástico, obviamente nos termos do capitalismo regulado sob o regime de acumulação taylorista-fordista, sob o investimento em educação, ao passo que países de outros continentes, como África e América Latina, apresentavam resultados inexpressivos, devido ao suposto atraso econômico. .

A sua gênese encontra-se no Projeto Regional do Mediterrâneo capitaneado e executado pela OCDE ${ }^{5}$, executado entre os anos 1950 e 1959, sob a assessoria de Francisco de Paula Leite Pinto, Engenheiro-Educador, Ministro da Educação Nacional de Portugal (1955-1961), que apresentou, em 1948, um planejamento educacional adequado aos interesses do crescimento econômico e modernização de seu país. A OCDE, tendo aceitado e considerado útil, aplicou o referido Projeto em outros países do Mediterrâneo (SILVEIRA, 2011, p. 241-242).

Na sequência, além de vasta publicação, eventos são realizados com o fito de difundir a ideologia do desenvolvimento, modernização e formação do capital humano.

A OCDE realizou, em Washington, a Conferência Crescimento Econômico e Investimento na Educação (1961), a UNESCO promoveu, em Santigo do Chile, o Encontro Educação e Desenvolvimento Econômico na América Latina (1962), o Banco Interamericano de Desenvolvimento (BID) constituiu a mesa-redonda Educação Superior e Desenvolvimento Latino-Americano (1965), realizada em Assunção, Paraguai. Os Jornais,

\footnotetext{
${ }^{4}$ Ressalta-se o papel dos organismos supranacionais, particularmente do Banco Mundial (BM), Organização para a Cooperação e o Desenvolvimento Econômico (OCDE), Organizações da Nações Unidas para a Educação, a Ciência e a Cultura (UNESCO) e, mais recentemente, do Setor Educacional do Mercosul (SEM) e da União Europeia, na elaboração e difusão, em nível mundial, da ideologia desenvolvimentista - que incorpora tanto o ideário da modernização quanto o de formação do capital humano como instrumento de redução do antagonismos entre classes sociais por mediação de intelectuais (orgânicos e cosmopolitas) junto ao aparelho estatal e às organizações da sociedade civil. Não é à esmo que, o mote da educação para a paz, capitaneado pela UNESCO, se manifesta em conferências, tratados e acordos, e se faz valer por mediação da Rede-Programa das Escolas Associadas à UNESCO (Rede-PEA), desde o ano de 1953, junto às escolas públicas e privadas.

5 Organismo sucessor da OECE, criada, em 1948, no contexto de aplicação do Plano Marshall. Em sua origem tinha ações limitadas ao espaço geográfico da Europa, Estados Unidos e Canadá, atualmente, a OCDE volta-se para a "cooperação e desenvolvimento econômicos" de diversos países do globo. Seus trabalhos sobre educação estão estreitamente ligados à ação governamental, particularmente nos setores da economia e emprego, com foco na formação do capital humano.
} 
revistas, agências nacionais de pesquisas econômicas, dentre outros intelectuais coletivos da sociedade civil e, sobretudo, do aparelho estatal exerceram papel crucial na difusão do ideário do investimento em ativos humanos. Destacam-se quatro publicações: Investment in Human Capital: a theorical analysis (BECKER, 1962), Human Capital: a theorical and empirical analysis with special reference to education (BECKER, 1964), ambas de Gary Becker, The economic value of education (SCHULTZ, 1963), Investment in Human Capital: the role of education and of research (SCHULTZ, 1971), de Theodore Schultz ${ }^{6}$

Além destas, foram publicados o Relatório Atcon - La Universidad Latinoamericana: clave para un enfoque conjunto del desarrollo coordinado social, económico y educativo en América Latina (1961), que teve influência marcante nas contrarreformas educacionais do Brasil, do Chile e de Honduras, e o Relatório Robbins (1963), aprovado pelo governo britânico, que encaminhou as modificações promovidas em França, Espanha e Alemanha. Ambos convergem no que diz respeito à organização de um sistema educacional que, hoje, faz parte da realidade brasileira, além de estarem em sintonia com a Recomendação da UNESCO de 1962, a que nos referiremos adiante.

Trata-se da criação de um sistema de ensino articulado, composto por universidades, escolas, faculdades, institutos isolados, institutos vinculados às universidades e instituições de formação profissional tecnológica de nível superior; a expansão do número de matrículas no ensino superior; a autonomia administrativo-financeira da universidade; o enquadramento de cursos de formação profissional tecnológica de nível médio no ensino superior; a transformação de faculdades avançadas de tecnologia em universidades tecnológicas; a expansão de institutos superiores de tecnologia; o aperfeiçoamento da pósgraduação com a criação de instituições especializadas no desenvolvimento da pesquisa de C\&T.

Todo esse arsenal político-teórico-ideológico assume estatuto de legitimação científica e econômica no quadro de expansão dos sistemas educativos, no final dos anos 1960 e início dos 1970, influenciando sobremodo os rumos das políticas educacionais de países europeus, membros da OCDE, e latino-americanos, membros da ONU.

Ressalta-se que, ao criticar a perspectiva teórica do capital humano, sobre o investimento econômico na educação, não se pode perder de vista o caráter contraditório entre capital, trabalho e educação e a defesa da classe trabalhadora em torno da educação pública-estatal, gratuita, de qualidade e socialmente referenciada, que exige do Estado (nos limites da sociedade capitalista) a aplicação de $10 \%$ do orçamento anual da União para a rede pública de ensino. Isto é, exige-se investimento em educação sem, no entanto, direcioná-la aos interesses imediatos do mercado e ao crescimento econômico. Trata-se de reivindicar o investimento em educação com vistas à formação do sujeito pleno, bem

6 Para uma análise crítica da educação como investimento em capital humano, bem como das teorias da escola reprodutivista, ver Vicenzi (1983) e Frigotto (2001). 
como ao desenvolvimento econômico-social, tecnológico e cultural autônomo do país e, por que não, da região latino-americana.

\section{A subsunção da política educacional à política de C\&T}

Finda a Guerra, já estava definido o lugar da América Latina na reconfigurada divisão internacional, sob a hegemonia estadunidense. O Brasil, visto tão somente como uma reserva estratégica que permitiria a continuidade do poderio econômico e militar dos E.U.A. e fonte fornecedora de matérias-primas de valor, vinha nos limites da "cooperação antagônica" (MARINI, 1977; 2000; 2012) dando continuidade à política nacionaldesenvolvimentista, iniciada no governo Vargas.

No entanto, qualquer política de desenvolvimento capitalista deveria considerar a necessidade de aprofundar a inserção do país no mercado internacional, acentuada com a criação da ONU e seu sustentáculo na região latino-americana, a Comissão Econômica para América Latina e Caribe (CEPAL).

Em meio ao debate ocorrido entre defensores do livre mercado, representados por Eugênio Gudin, e aqueles que advogavam que o país só alcançaria a industrialização por meio de um Estado forte, provedor da industrialização que adotasse a política de substituição de importação e de reserva de mercado, liderados por Roberto Simonsen (SILVEIRA, 2008, p. 2), foi criada, em 1951, a Comissão Mista Brasil-Estados Unidos para o Desenvolvimento Econômico, vinculada ao Plano Americano de Assistência Técnica para América Latina (Ponto IV), com o fito de formar a infraestrutura brasileira nos setores do transporte, de energia elétrica, da agricultura e alguns poucos projetos de cunho industrial. Enquanto isso, o governo brasileiro elaborava o plano SALTE (saúde, alimentação, transporte e energia) para o período 1949-1954

Os projetos foram financiados em parte pelo Banco Mundial e o Export-Import Bank (EXIMBANK), do lado estrangeiro, e pelo recém criado BNDE, hoje Banco Nacional de Desenvolvimento Econômico e Social (BNDES). Este assumiu o encargo de administrar, em moeda local, os recursos do empréstimo feito pelos dois primeiros e de viabilizar a implantação e implementação das políticas consideradas fundamentais para o crescimento econômico.

No entanto, segundo Marini (2000, p. 85), a execução desse projeto de financiamento veio a ser obstruída pelo próprio governo estadunidense, sob a presidência de Dwight Eisenhower, com o fito de impedir a burguesia brasileira acessar recursos que the permitissem superar, com relativa autonomia, os pontos de estrangulamento surgidos no processo de industrialização e, assim, forçar-lhe a aceitar o investimento externo direto (IED). Daí por diante, a burguesia brasileira assumirá o papel de sócia menor em alianças com os capitais estrangeiros, aprofundando a dependência econômica, educacional, tecnológica e cultural a tal ponto que, hoje, o bloco no poder não deixa dúvidas quanto à 
sua opção: é preferível salvar o mercado de consumo, atual base do crescimento econômico, do que vidas.

De volta à nossa questão, coube ao BNDE, primeiro, instituir a Cota de Educação e Treinamento Técnico, em 1958, como instrumento financiador do "progresso técnicocientífico"; depois, constituir o Fundo tecnológico (FUNTEC), em 1964, com o objetivo de ajustar o planejamento e a organização do ensino técnico-profissional, do ensino de engenharia e da pesquisa de C\&T, aos interesses econômicos.

As contrarreformas educacionais incorporam alguns elementos de debates da década anterior, contudo fortemente balizadas pelo Acordo MEC-USAID (Ministério da Educação e Cultura e United States Agency for International Development) e, mais tarde, pelo Acordo MEC-BIRD ${ }^{7}$, o que permitiu à comissão elaboradora do FUNTEC decidir sobre o destino e a distribuição dos recursos nos cursos de graduação e pós-graduação do ensino de engenharia, definindo o modelo de pós-graduação que se pretendia para atender ao projeto de crescimento econômico dependente, associado e subalterno.

Os recursos foram assim destinados: a) 40\% à manutenção de cursos de mestrado e doutorado em Física, Química, Engenharia Química, Engenharia Metalúrgica, Engenharia Mecânica, Engenharia de Eletricidade; b) $60 \%$ às pesquisas técnico-científicas voltadas para projetos pilotos no campo da indústria de base. Em caráter excepcional, parte dos recursos poderia financiar projetos no nível médio do ensino técnico (BRASIL, 1969).

Naquele contexto, já, era "notória a introdução de concepções que degradam e subestimam o ensino público, enaltecendo o ensino privado e que acabam por fortalecer a ideia de que a educação, para ser responsável, precisa ser sobretudo uma mercadoria" (FERNANDES, 1986, p. 30. Itálico do autor). Também, fica clara, a hierarquização dos ramos do saber segundo a contribuição imediata que podem oferecer à produção, particularmente por mediação da pesquisa aplicada.

Tornado um fundo de desenvolvimento técnico-científico, essencial ao rendimento eficiente da expansão do setor industrial, modernização da agropecuária e ampliação de serviços afins, o FUNTEC foi instituído em meio a gênese da concepção de educação tecnológica, quando engenheiros-educadores, intelectuais orgânicos de vultosos aparelhos hegemônicos, propugnavam a criação de cursos tecnológicos, depois denominados, pela política educacional, cursos de engenharia de operação.

7 O acordo MEC/BIRD, assinado em 1971, foi um convênio guarda-chuva para se colocar em prática a contrarreforma educacional do governo empresarial-militar. O PRODEM (Programa de Desenvolvimento do Ensino Médio e Superior de Engenharia de Operação), órgão executor, levou nove anos para realizar o projeto, contando, inicialmente, com 21 milhões de dólares do BIRD, para construir prédios; equipar oficinas e laboratórios; capacitar "recursos humanos", em todos os níveis. 
Embora não estivesse tão clara, o FUNTEC expressava a necessidade de criação de um sistema todo articulado de ensino que viesse responder aos processos de internacionalização da economia/tecnologia sob a coordenação integrada dos ministérios da economia, da C\&T e da educação. Engendrava-se, assim, a subsunção real das políticas educacionais aos desígnios do capital por mediação da política de C\&T, que será consolidada nos anos 1990, como veremos na sequência.

\section{A concepção e abrangência da educação tecnológica}

Junto à difusão da ideologia desenvolvimentista, mediada pela formação do capital humano, a Recomendação Internacional sobre Ensino Técnico e Profissional elaborada pela UNESCO, em 1962, orientava os sistemas educacionais a promover a educação para a vida em uma era tecnológica. Tal movimento, nos termos de Antonio Gramsci, vinha engendrar uma reforma intelectual, moral e cultural, com base, é claro, em uma reforma econômica, de modo a subsumir a produção do conhecimento (novo e inovador) e, por conseguinte, a subjetividade do trabalhador, à racionalidade instrumental da acumulação capitalista. Embora a subsunção real da subjetividade do trabalhador venha acontecer em fins do século XX e início do XXI, sob o ideário da sociedade do conhecimento/economia do conhecimento, é possível afirmar que, no Pós Segunda Guerra, o capital dava os primeiros sinais de que já não lhe bastava somente explorar a objetividade do trabalho.

A Recomendação indicava que os planos de ensino técnico e profissional destinados a formar pessoal para as áreas da indústria, agricultura, comércio e serviços afins, além de levaram em conta a rápida evolução da tecnologia, deveriam também elevar o patamar de escolarização, de modo que a formação técnica e profissional deveria ser oferecida em três níveis de ensino, qualificação, formação de técnicos, formação de engenheiro (tecnológico/operacional e pleno). Assim, a palavra tecnológica será vinculada à educação, ganhando fluência nos documentos oficiais do $\mathrm{MEC}^{8}$.

Termos como educação técnica, formação técnico-profissional, ensino profissional, ensino industria/ passam a ser substituídos, no âmbito do MEC, por educação tecnológica. Nesta perspectiva, o Parecer no 60/63 do CFE instituiu o curso de engenharia de operação, com três anos de duração, cujos currículos mínimos foram definidos no Parecer no 25/65, estipulando o perfil do engenheiro de operação como elemento de formação profissional-

\footnotetext{
${ }^{8}$ Os termos dessa Recomendação estiveram presentes em documentos emanados não apenas pelo Conselho Federal de Educação (CFE), na década de 1970, mas também pela Secretaria de Ensino Médio e Técnico (MEC/SEMTEC) dos anos de 1990, mantidos pela atual Secretaria de Educação Profissional e Tecnológica (SETEC), a exemplo do estabelecimento de três níveis de ensino, na formação profissional — "ensino para a formação de trabalhadores qualificados", "ensino para a formação de técnicos" e "engenheiros e quadros superiores".
} 
tecnológica, de nível superior, distinto de engenheiros com cursos de formação profissional científica, que não deveriam ser confundidos com os primeiros devido à preparação científica muito mais ampla, oferecida em cursos de longa duração ${ }^{9}$.

Não só o referido Parecer nำ25/65, como, também, outros documentos emanados do MEC aderiram à expressão formação profissional-tecnológica, primeiro, por relacioná-la ao desenvolvimento das forças produtivas e, depois, por se referir a cursos enquadrados no ensino superior, oferecendo-lhes um cunho diferenciado dos cursos técnicos de nível médio tidos, até então, como de formação técnico-profissional ${ }^{10}$.

No mesmo ano de 1965, foi aprovado o Parecer no 977 - conhecido por Parecer Sucupira - que dá Definição aos cursos de Pós-Graduação, bem como se cria o Fundo de Financiamento de Estudos e Projetos e Programas (FINEP). Alocado no BNDE e financiado com recursos do BID e da USAID, o Fundo tinha como objetivo investir em programas e propostas de investimento na área da C\&T (LONGO; DERENUSSON, 2009, p. 2) para a indústria e modernização do país. Entrementes, no ano de 1967, cria-se a uma empresa estatal, vinculada ao Ministério do Planejamento, com a mesma sigla do Fundo, denominada Financiadora de Estudos e Projetos (FINEP), que atua até hoje como agência de financiamento reembolsável e não reembolsável de programas voltados muito mais para a inovação do que pesquisa básica.

A FINEP veio substituir e ampliar o papel, até então, exercido pelo FUNTEC/BNDE, passando a financiar a implantação de programas de pós-graduação nas universidades brasileiras. A partir de 1968, a institucionalização da política de C\&T ganha espaço no Plano Estratégico de Desenvolvimento (PED), que engendrou a criação do FNDCT pelo DecretoLei no 719/1969 (BRASIL, 1969). Durante os anos 1970, afirma Longo (2009, p. 4), a FINEP foi incorporada ao FNDCT, como uma espécie de secretaria executiva, quando contou com,

\footnotetext{
9 Neste contexto, os cursos tecnológicos já eram oferecidos em Volta Redonda e São Bernardo do Campo, mantidos, respectivamente, pela Escola Fluminense de Engenharia e pela Faculdade de Engenharia Industrial, que funcionavam em estreita articulação com empresas do ramo para organização dos currículos e oferta de estágio aos alunos. No final da década de 1960 foram criados os cursos de tecnólogos no Centro Estadual de Educação Técnica do Estado de São Paulo e no Centro de Educação Técnica da Amazônia, hoje Centros de Educação Tecnológica. Os cursos de Engenharia de Operação foram também implantados, em 1966, na então Escola Técnica Federal da Guanabara, o hoje CEFET-RJ-sede Maracanã.

10 A expressão Educação Profissional ganha fluência na política educacional do ministério Paulo Renato, posto que até então o termo corrente entre educadores era formação técnico-profissional. O primeiro projeto de LDB apresentado na Câmara Federal, em 1988, no Capítulo III, o Da Educação Escolar de 2 grau, tinha como objetivo geral da educação de 2 grau a formação politécnica. Após sofrer várias alterações, o substitutivo de Jorge Hage incorpora ao texto um capítulo específico, o Da formação técnico-profissional; esse capítulo tem sua nomenclatura modificada no substitutivo de Darcy Ribeiro (95/96) para Educação Profissional, sendo, então, transformada, no governo FHC, em uma modalidade de educação, distinta e separada do ensino regular — a Educação Básica.
} 
aproximadamente, U\$ 72 milhões provenientes do BID. Neste contexto, foram transferidos volumosos recursos para a Comissão de Aperfeiçoamento de Pessoal de Nível Superior (CAPES) e o Conselho Nacional de Pesquisa (CNPq).

O FNDCT cumpriu papel decisivo na expansão dos cursos de pós-graduação e, notadamente, na implantação do Plano Básico de Desenvolvimento Científico Tecnológico (PBDCT), publicado em $1973^{11}$, bem como no processo de constituição do sistema nacional de C\&T, ocorrido até o final dos anos de 1980. Contudo, é preciso apreender o FNDCT como uma das mediações que fortalece a associação e dependência econômica, educacional e tecnológica do capitalismo brasileiro ao/do capital-imperialismo central. Hoje, o FNDCT possui aporte financeiro significativo, englobando os Fundos Setoriais de Ciência e Tecnologia (FS), com vistas a financiar a inovação e o desenvolvimento científicotecnológico do país.

No que diz respeito ao I PBDCT, pretendemos ressaltar sua importância nos rumos da atual política de CT\&I, no Brasil, pois que ele definia claramente o lugar subalterno da produção do conhecimento em relação ao crescimento econômico e tensionava o debate em torno da relação universidade, pesquisa e setor privado, coerentemente, ao Primeiro Plano de Desenvolvimento Nacional (I PND) para o biênio 1972-74.

O I PND executou um projeto de Brasil Potência, entretanto, dependente, associado, subalterno, excludente e periférico, visto que aponta para

\begin{abstract}
aceleração e orientação da transferência de tecnologia, [porém] associada a forte componente de elaboração tecnológica própria, segundo este programa, estabelecido para o período 1972/74: I - Operação do sistema financeiro para o desenvolvimento tecnológico, compreendendo, notadamente, o Fundo Nacional de Desenvolvimento Científico e Tecnológico (FNDCT), o FUNTEC (BNDE), o fundo associado ao Conselho Nacional de Pesquisas (CNPq) e o FUNAT (INT) [...] Incumbido de promover e coordenar o programa geral, em articulação com o Ministério do Planejamento e Coordenação Geral, o Conselho Nacional de Pesquisas (CNPq) está tendo a sua estrutura fortalecida e modernizada [...] V - Integrar Indústria-Pesquisa-Universidade, como núcleo fundamental de uma estrutura nacional integrada de Educação/Ciência-Tecnologia/Empresa. Essa integração deverá ser impulsionada mediante: disseminação e consolidação dos centros de integração Universidade-Indústria ou Escola-Empresa, para assegurar programas sistemáticos de estágios de estudantes em empresas, para comunicar ao sistema universitário as necessidades quantitativas e qualitativas do setor privado quanto à formação de profissionais, e para permitir a realização conjunta de projetos de pesquisa. Adoção, pelas instituições de pesquisa governamentais, de programa sistemático de articulação com o setor produtivo nacional, principalmente para disseminação do resultado de seus estudos. Realização de convênios do Governo com as Universidades, para que estas procedam (isoladamente, ou em conjunto com entidades governamentais) a estudos de desenvolvimento regional, ou a pesquisas aplicadas, de interesse do planejamento econômico e social. Ampliação dos esquemas de participação do estudante nos programas de desenvolvimento, a exemplo do Projeto Rondon, da Operação Mauá e do Projeto Integração (BRASIL, 1971, p. 55-59).
\end{abstract}

O Projeto Rondon, a Operação Mauá e o Projeto Integração envolveram número significativo de estudantes, professores e técnicos administrativos, tornando-se mediações,

\footnotetext{
11 Este, tendo sido I PBDCT (1973-1974), foi seguido pelo II PBDTC (1976-1979) e III PBDCT (1980-1985).
} 
junto ao Ato Institucional $n^{\circ} 5$, para abafar a crise de hegemonia do regime e responder à efervescência política que se manifestava na sociedade brasileira, particularmente no ano de 1968, quando eclodiu o movimento estudantil e a Passeata dos Cem Mil.

Neste contexto, a contrarreforma universitária, em curso desde promulgada a Lei $\mathrm{n}^{\circ}$ 5.540/1968, sob os substanciais recursos do FNDCT/FINEP (LONGO; DERENUSSON, 2009, p. 5), materializava a concepção veiculada pelo Relatório Atcon de que, as modificações estruturais da universidade requeriam, no plano sociopolítico, "a transição do ensino de elite para o ensino de massas"; no plano tecnológico, "a transformação de instituições meramente acadêmicas em institutos de ciência pura e aplicada"; e, no plano econômico, "a transformação de torres de marfim em instituições a serviço da comunidade [empresarial]" (ATCON, 1961, p. 22) ${ }^{12}$.

Desse modo, a universidade, atuando do topo da sociedade, promoveria uma reforma socioeconômica, possibilitando, assim, a região latino-americana, particularmente o Brasil cumprir seu papel na economia que se internacionalizava.

Homem de seu tempo, Florestan Fernandes apreendeu a questão do planejamento conjugado entre economia, política de C\&T e educação.

\begin{abstract}
Qualquer que seja o setor que examinemos: da Física à Sociologia, o progresso científico é contado pela capacidade das nações de mobilizar, organizadamente, seus recursos em benefício da posição delas na estrutura internacional de poder. [...] Reconhecidamente ou não, o planejamento tornou-se o símbolo organizatório da civilização produzida pela ciência [e tecnologia]. Limitando-nos ao que nos interessa, parece claro que, a era do planejamento, dando primazia ao conhecimento das técnicas de controle racional das situações, concede primazia à fase de exploração prática das descobertas científicas. A teoria tornou-se sob muitos aspectos, instrumental, prevalecendo o objetivo de convertê-la de 'saber sobre alguma coisa' em 'saber para alguma coisa' (FERNANDES, 1959, p. 15).
\end{abstract}

Depois de sessenta e um anos das palavras de Florestan Fernandes, a instrumentalização do conhecimento e a ideologia da formação do capital humano, com vistas a inserção competitiva do país no mercado mundial, não foram abandonadas sequer por governos tidos como social-democratas e/ou progressistas. Elas fazem parte do fio condutor da história da educação brasileira. Basta remeter para o atual governo Bolsonaro, abertamente anticiência, que busca fragilizar toda e qualquer área do conhecimento, sobretudo, as ciências humanas e sociais aplicadas.

Recentemente, a Portaria MCTIC $n^{\circ} 1.122 / 2020$, em alinhamento com o Plano Plurianual (PPA) 2020-2023, elaborada à revelia do debate público, desconsiderou por

12 Destaca-se que, Rudolph Atcon assessorou Anísio Teixeira no processo de implantação da CAPES, trabalhando como subdiretor do Programa Universitário entre 1953 e 1956. Por sua vez, Anísio Teixeira, apreciador que foi da sociedade norteamericana, de seus princípios liberais e da organização administrativo-pedagógica da escola nova e da universidade que lá se desenvolveu, sua proposta de reforma universitária pouco se distanciava da proposta governamental, promovida pelo MECUSAID (Cf.: TEIXEIRA, 1988, p. 154-181). 
completo a contribuição da pesquisa básica produzida no âmbito das Ciências Humanas e Sociais, bases fundamentais da produção do conhecimento. Entretanto, ante o movimento de entidades científicas no seio da sociedade civil, o MCTIC, por meio da Portaria $\mathrm{n}^{\circ}$ $1.329 / 2020$, veio modificar a referida Portaria $n^{\circ} 1.122$ e incluir projetos de pesquisa básica, humanidades e ciências sociais também como "prioritários, diante de sua característica essencial e transversal" (BRASIL, 2020), junto a outros voltadas para as áreas de tecnologias.

\subsection{O lugar das Ciências Humanas e Sociais Aplicadas}

Apesar do milagre econômico brasileiro (1967-1974), as mazelas sociais se aprofundavam e a ideologia da formação do capital humano parecia não justificar a relação entre investimento em educação e aumento salarial ${ }^{13}$. A justificativa governamental, nas palavras de Mario Henrique Simonsen e Roberto de Oliveira Campos, manifestava-se da seguinte maneira:

A principal razão para a piora da distribuição de renda parece ter sido a inadequação do perfil de qualificação da mão-de-obra em relação à exigências do mercado, [identificando] os desníveis educacionais com a principal razão das diferenças individuais de renda (SIMONSEN; CAMPOS, 1975 apudBRUM, 1982, p. 119).

Fato é que, o governo empresarial-militar modificou apenas as relações de dependência do modelo econômico anterior. Mantendo o IED, o Brasil seguiu copiando e adaptando C\&T (OLIVEIRA, 2003), o que teve e tem implicações ético-políticas sérias na formação da força de trabalho, particularmente da classe trabalhadora. Os monopólios e respectivas $P \& D$ reforçaram a enorme vantagem do capital-imperialismo central sobre os demais. O fosso científico-tecnológico evidencia a especificidade do capitalismo brasileiro, cuja política educacional não propiciou, até hoje, uma sólida formação das bases científicotecnológicas, histórico-geográficas e culturais para as crianças, jovens e adultos.

Entretanto e à despeito de a pedagogia oficial buscar separar a formação de cultura geral da formação técnica-tecnológica e estas da ciência, da atualidade e do trabalho socialmente necessário, o desenvolvimento das forças produtivas passou a exigir, cada vez mais, a interdisciplinaridade na formação do "trabalhador coletivo" (MARX, 2004). Sendo a essência da tecnociência, a interdisciplinaridade vem chamando à produção de C\&T as Ciências Humanas e Sociais Aplicadas. O complexo político militar-industrial do Estado, o empresariado junto aos laboratórios de $P \& D$, e a universidade, formam, assim, nichos de produção e socialização do conhecimento no âmbito do SNCTI no tocante aos projetos

${ }^{13} \mathrm{~A}$ força de trabalho é fonte de valor, cria valor e deposita mais-valor na mercadoria. Assim, o salário só pode ser visto como expressão do trabalho livre e alienado sob o jugo do capital. O salário é, tão somente, a quantidade de dinheiro-mercadoria necessária à subsistência do trabalhador, que possui apenas sua força de trabalho. Neste sentido salário não pode ser confundido com renda (Cf.: MARX, 2006). 
nos setores da cibernética, da neurociência, da computação, da biotecnologia, de energias renováveis, do tratamento de poluição, monitoramento, prevenção e recuperação de desastres naturais e ambientais (CASANOVA, 2006, p. 22-25).

Existe, pois, uma linha tênue entre as Ciências Exatas e da Terra, as Engenharias, as Ciências da Saúde, as Ciências Agrárias, as Ciências Humanas, as Ciências Sociais Aplicadas, a Linguística, Letras e as Artes, sendo a Educação transversal a todas elas, o que subverte a pretensa divisão sociotécnica do trabalho de intelectuais pesquisadores (Idem). Afinal, o trabalho e a educação são mediações dos processos sociais da existência humana, fundamentais no processo de produção e reprodução da vida humana e do conhecimento por ela produzido no processo histórico-social.

\begin{abstract}
A natureza não constrói máquinas, locomotivas, estradas de ferro, telégrafos, teares automáticos etc. São produtos da engenhosidade humana; são materiais naturais que se transformam em instrumentos da vontade e da ação humanas sobre a natureza. São como órgãos do cérebro humano criados pela mão humana; conhecimento objetivado. O desenvolvimento da maquinaria revela até que ponto o conhecimento social geral converteuse em força produtiva imediata; portanto, até que ponto as condições do próprio processo da vida social foram submetidas ao intelecto coletivo e remodeladas por ele. Até que ponto as forças produtivas sociais são produzidas, não apenas, sob a forma de conhecimento, mas também, como órgãos imediatos da práxis social (MARX, 2009, p. 229-30).
\end{abstract}

No entanto, é raro o intelectual, em sua acepção gramsciana, que apreende a C\&T como resultado do trabalho coletivo, exercido no âmbito da universidade, de institutos, como o Oswaldo Cruz, o IME, O IMPA, O IPEA, de associações nas áreas das ciências humanas e sociais, de centros de pesquisa e documentação, de museus e, sobretudo, da Educação. O senso comum remete, de modo geral, para o fetichismo da C\&T segundo o qual o desenvolvimento aparece como algo autônomo frente às relações de produção e reprodução da vida ampliada.

Tal concepção fetichizada entende a organização da produção, controle e regulação da força de trabalho, como resultado de uma demanda tecnológica, de modo que C\&T, supostamente, determinariam o crescimento econômico e o processo social ontológico na direção de uma sociedade igualitária. É neste sentido que ocorre a "circularidade da teoria do capital humano" apontada por Frigotto (2001).

O que não pode se perder vista é o fato de que, as Ciências Humanas e as Socais Aplicadas constituem-se em quadro tenso e contraditório porquanto se manifestam tanto como instrumento à serviço da classe dominante, quanto expressão de um movimento teórico-empírico que busca a transformação das relações sociocapitalistas.

Sem elas, sem a Educação, não seria possível a formação de novas subjetividades por mediação da escola/universidade, locus privilegiado de organização e sistematização do conhecimento produzido social e historicamente e de formação de diferentes camadas de intelectuais (GRAMSCI, 2001).

Toda reforma moral e intelectual (força espiritual) ocorre em nível do Estado Integral, por mediação dos aparelhos hegemônicos (estatais/públicos e privados), com base na 
reestruturação produtiva e na (des)regulamentação da força de trabalho, de modo que todos os sujeitos em sociedade (burgueses e trabalhadores) comportem-se coerentemente com o vigente modelo de produção. "É por isso que, uma reforma intelectual e moral não pode deixar de estar ligada a um programa de reforma econômica; mais precisamente, o programa de reforma econômica é exatamente o modo concreto através do qual se apresenta toda reforma intelectual e moral" (GRAMSCI, 2007, CC. 13, §1, p. 19).

Do ponto de vista ético-político-práxico, a questão é bem mais ampla, na medida em que implica enfrentar e romper com a proposta burguesa de educação tecnológica, de como o homem se relaciona com a natureza (subjetiva e objetiva), bem como dilacerar os grilhões da propriedade privada a da divisão sociotécnica do trabalho.

\subsection{A diversificação da oferta de cursos}

No bojo da política governamental de expansão do denominado Sistema de Ensino Superior (Cf. BRASIL, 1978). formado por instituições das redes federal, estadual, municipal e privada, foram criados não apenas os campi universitários, mas também três escolas técnicas federais foram elevadas ao status de educação superior, quando transformadas, pela Lei no 6.545/1978, em Centros Federais de Educação Tecnológica (CEFETs) do Rio de Janeiro, de Minas Gerais e do Paraná. As referidas escolas técnicas já vinham oferecendo os cursos de engenharia de operação, também chamados de cursos tecnológicos, em meio à gênese da concepção de educação tecnológica.

Neste quadro desvela-se que, a diversificação da oferta de cursos ocorre em diferentes áreas do conhecimento, incluídas, aí, as Ciências Humanas, a Formação de Professores para Educação Especial, a Linguística e Letras, a Arte, a Saúde e as Ciências Biológicas, Medicina e Enfermagem, além das Exatas e Tecnológicas e Engenharias.

Com este reordenamento do ensino superior, o Departamento de Assuntos Universitários (DAU/MEC) buscava, de um lado, conter a entrada da classe trabalhadora nos cursos tradicionais de longa duração oferecidos pelas universidades públicas e, de outro, sustentar a explosão do número de matrículas nas instituições privadas ${ }^{14}$, sobretudo nos cursos superiores de tecnologia, mas também em cursos de longa duração cujo ensino não fazia nenhuma articulação com a pesquisa e a extensão. Tal medida já havia sido preconizada pela Equipe de Assessoria ao Planejamento do Ensino Superior (EAPES), no período de 1965 a 1968.

Pode ser que nosso País por muito tempo ainda não esteja em condições de oferecer a todos os candidatos a oportunidade de ingressar nas Universidades para obter um diploma de habilitação profissional. Contudo, com um esforço bem programado, nossas instituições de ensino superior poderiam atingir desde logo um número muito maior de pessoas, se fossem abertas a um campo extremamente importante de sua possível atividade que é o da extensão

\footnotetext{
${ }^{14}$ Mantido pelo Programa Crédito Educativo (CREDUC), como nova fonte de financiamento.
} 
universitária [...] No campo da formação profissional, as Universidades e escolas isoladas de ensino superior têm a possibilidade de organizar cursos de especialização, de adaptação e de atualização, acolhendo em seu seio não só profissionais já formados, mas também pessoas sem nível universitário que estejam em condições de se aproveitarem da iniciativa, que lhes dará nova habilitação no exercício de atividades necessárias ou úteis ao desenvolvimento do País (BRASIL, 1969, p. 114).

No âmbito do Projeto Prioritário 15 - Implantação de Cursos de Curta Duração ${ }^{15}$ é possível afirmar mais uma vez a abrangência da concepção burguesa de educação tecnológica,

[...] a diversificação das tarefas ocupacionais, de produção de bens e serviços, de administração e gerência, produzida pelo progresso tecnológico solicita ao sistema [de ensino superior] além dos cursos tradicionais de longa duração, outras habilitações intermediárias, para fazer face às crescentes necessidades de recursos humanos. A resposta a esse apelo vem sendo a implantação de cursos de tecnólogos, com duração média de dois anos e caráter terminal, em instituições de nível superior já existentes ou em centros especialmente criados para esse fim, visando atender às exigências nacionais e regionais [...] Desafoga-se a Universidade de pressões que não pode suportar e de apelos que não está em condições de atender; favorecem-se inovações no sistema pós-secundário, assumindo as funções do ensino tecnológico, voltado para a aplicação dos conhecimentos, descentralizando-se. dessa forma, as tarefas de educação superior; e, finalmente, é oferecida uma alternativa para a imensa gama de jovens em busca de um título de qualificação superior, que lhes proporcione realização pessoal e meios de subsistência condizentes, obtido em cursos menos demorados e por isso menos dispendiosos (BRASIL, 1978, p. 47).

Foram criados os cursos de: Peripatologia [sic! $]^{16}$ e Fonoaudiologia (Escola Paulista de Medicina), Couros e Tanantes (UFPA), Indústria Têxtil (UFRN), Obras de Solos e Construção Civil (Faculdade de Engenharia de Limeira), Produção de Couros e Calçados (Federação de Estabelecimentos de Ensino Superior de Novo Hamburgo), dentre outros.

Ao longo dos anos 1980 todo este arcabouço em torno de um sistema de ensino superior foi tido como válido e eficaz.

Neste contexto, a educação tecnológica seria mais abrangente do que a formação técnico-profissional, e, portanto, associada a um nível maior de conhecimento, envolvendo questões relacionadas ao desenvolvimento de novas tecnologia e, sobretudo, interessada ao mercado, incorporados os três setores da economia, de modo a formar diferentes capacidades de trabalho.

\subsection{O que é a concepção de educação tecnológica burguesa}

Entre os anos de 1985 e 2001, quando foram realizadas, respectivamente, a $1^{\text {a }}$ Conferência Nacional de Ciência e Tecnologia e a $2^{\mathrm{a}}$ Conferência Nacional de Ciência,

\footnotetext{
${ }^{15}$ O referido Projeto integra o Relatório do DAU/MEC (BRASIL, 1978), citado anteriormente.

16 Talvez o Documento se refira à patologia peri-implantar, uma alteração patológica dos tecidos ao redor dos implantes odontológicos.
} 
Tecnologia e Inovação (CNCT\&I), ocorreram modificações significativas nas formas e fontes de financiamento da produção do conhecimento, cujo arcabouço normativo-legislativo veio a ser aprofundado nas $3^{a}$ e $4^{a}$ CNCT\&I, realizadas em 2005 e 2010, respectivamente. Enquanto a $1^{\text {a }}$ CNCT\&I buscou ampliar a participação da sociedade civil organizada em torno da consolidação da política científico-tecnológica brasileira, a $2^{\text {a }}$ CNCT\&I enfatizou a importância da inovação tecnológica como instrumento para a competitividade, passando a agregar o termo "inovação" em sua denominação.

A produção de inovação passa a desempenhar papel central no novo modelo de produção, denominado por Harvey (2005) de regime de acumulação flexível. Inseridos neste quadro, os organismos supranacionais intensificam indicações sobre o cumprimento de metas, por parte dos Estados-Nações, sobretudo no campo educacional.

Promove-se a interdependência entre o projeto de modernização, a capacitação tecnológica e os rumos do sistema educacional - uma preocupação marcante e histórica dos sucessivos governos, sobretudo no que tange às políticas de formação de pessoal qualificado -, e consolida-se o SNCTI ou à subsunção da política educativa à política de CT\&I.

Esta concepção em sua fase amadurecida se materializou, primeiro, no processo de "cefetização", ocorrido nos anos de 1990, quando os CEFETs ${ }^{17}$ já não tinham como finalidade precípua formar apenas pessoal qualificado para indústria, posto que sua atuação ampliou-se, horizontalmente, voltando-se para os setores primário e terciário da economia e, verticalmente, para oferta, além de bacharelados, licenciaturas e cursos superiores de tecnologia, de cursos de pós-graduação stricto sensu e lato sensu.

Depois, no ano de 2008, quando a Lei no 11.892 modificou a denominação do conjunto destas instituições para Rede de Educação Profissional, Científica e Tecnológica (RFEPCT), transformando a maioria dos CEFETs em Institutos Federais de Educação, Ciência e Tecnologia (IFETs), respeitada a opção das comunidades internas ao CEFET-RJ e ao CEFETMG que, ao pleitearem sua transformação em universidade tecnológica tal como ocorreu com o CEFET-PR ${ }^{18}$, optaram por manter-se sob o antigo modelo CEFET. Hoje, esta Rede é

17 O processo de "cefetiz̧ação" foi iniciado no final da década de 1980, quando algumas Escolas Técnicas Federais a exemplo das de Pelotas, Campos, Pará, Pernambuco, Rio Grande do Norte, Mato Grosso, São Paulo, Maranhão e Bahia reivindicavam a sua transformação em CEFETs, enquanto outras pleiteavam o direito de ministrar cursos de nível superior. Lograram êxito, no entanto, as Escolas Técnicas do Maranhão e Bahia, transformadas em CEFETs, respectivamente, pela Lei no 7863/1989 e Lei no 8711/1993. As demais foram transformadas em bloco pela Lei no 8.948/1994, que, por sua vez, também instituiu o Sistema Nacional de Educação Tecnológica. É também na década de 1990 que o governo federal promove uma identidade entre educação profissional e educação tecnológica.

18 O CEFET-PR foi transformado, no ano de 2004, em Universidade Federal Tecnológica do Paraná (UFTPR). 
composta de IFETs, CEFETs, escolas técnicas vinculadas às universidades federais (ETVs), uma UT e o Colégio Pedro II, que é regido pelos mesmos instrumentos legais das demais instituições.

O Colégio Pedro II, ao integrar a RFEPCT, é mais um elemento revelador da abrangência da concepção de educação tecnológica, na medida em que, ele possui reconhecimento social e destaca-se no cenário nacional como instituição especializada na oferta da educação básica, de formação propedêutica.

Dos anos 1990 em diante, o sistema educacional brasileiro tornou-se, cada vez mais, complexo e articulado. Ampliou-se o leque de ofertas formativas, em todos os níveis e modalidades de ensino, hierarquizou-se as instituições de ensino segundo os ramos do saber, oferta e duração dos cursos. Esta totalidade, articulada e marcada por contradições entre capital, trabalho e educação, opera sob a envergadura da educação tecnológica, cuja concepção se materializa na formação de uma capacidade de trabalho socialmente combinada.

\section{À guisa de conclusão}

Se, no passado, o progresso técnico centrava-se na indústria, nos dias que correm, a inovação penetra todos os setores da produção, incluídos os serviços e a agricultura, tornando-se capaz de gerar e sustentar ciclos prolongados de crescimento da economia. Nos limites do ideário schumpeteriano ${ }^{19}$, a inovação possui dupla dimensão: de um lado, no plano micro, torna-se essencial para reduzir custos e aumentar a produtividade, não apenas da empresa, mas também da cadeia de valor; de outro, em nível macro, permite ganhar produtividade sustentável, sendo central para taxas de crescimento mais elevadas (SILVEIRA, 2011)

$\mathrm{Na}$ contemporaneidade, entende-se que a inovação dita as condições e a velocidade da produção do conhecimento uma vez que, supostamente, não é o trabalho que produz a riqueza da sociedade, mas sim o conhecimento. Nesta perspectiva ideológica da sociedade do conhecimentoleconomia do conhecimento, quanto maior a produção de CT\&I, maiores seriam as possibilidades de transformações econômicas e sociais na direção de uma sociedade coesa, igualitária e democrática. Daí, nas últimas décadas, o

19 Para Joseph Schumpeter, o pilar central do desenvolvimento encontra-se no empresário inovador que, por meio da ciência e tecnologia aplicadas, introduz novas mercadorias no mercado, abrindo novo ciclo econômico, a tal ponto que, passa a ser imitado por outros empresários, levando a todos à concorrência, até que esta elimine os lucros provenientes da inovação. Ao mesmo tempo, o empresário é visto como sujeito da mudança pois estimula o consumo e educa os consumidores. Daí, a ideia de "destruição criadora" que consiste em criar hábitos de consumo ante a suposta obsolescência de produtos antigos (Cf.: SCHUMPETER, 1997). 
conhecimento científico exercer liderança no processo de inovação com a institucionalização da pesquisa pública e privada, materializada nas universidades, CEFETs, IFETs, institutos de pesquisa, departamentos de $P \& D$ e, mais recentemente, nas escolas de ensino médio ${ }^{20}$.

Com o desenvolvimento histórico da concepção de educação tecnológica, desde a década de 1960, a política educacional (em todos os níveis e modalidades de ensino) veio sendo subsumida à política de C,T\&I, em um movimento tal que, engendrou a organização de um sistema de ensino todo articulado, com amplo leque de oferta formativas, que responde às dinâmicas do processo de internacionalização da economia \tecnologia. Na medida em que o capital se desenvolve, ele modifica a forma de socialização do trabalho sem dispensar, no entanto, formas pretéritas de trabalho. Exige, assim, o dinamismo de todas as partes do "trabalhador coletivo", cujas funções, socialmente combinadas, são realizadas por meio do trabalho complexo e do trabalho simples. Enquanto este se caracteriza mais pelo dispêndio da força de trabalho que "todo homem comum, sem educação, possui em seu organismo", aquele "emprega-se em trabalho superior, requerendo, pois, maior tempo de formação e com altos custos, e materializa-se em valor proporcionalmente mais elevado (MARX, 2004, p. 211-231).

Estamos falando, portanto, da capacidade de trabalho socialmente combinada, segundo a divisão internacional do trabalho que se generaliza a partir da articulação associada entre forças produtivas e expansão do capital., em escalas nacional, regional e internacional.

É, nestes termos que a concepção burguesa de educação tecnológica se materializa.

Concordamos, pois, com Gramsci (2001, CC. 12, § 2, p. 49) ao afirmar que, se a proposta é destruir essa trama, deve-se combater a multiplicação e hierarquização das ofertas educativas e lutar pela criação da escola única que busca formar crianças, jovens e adultos para analisar criticamente a realidade, escolher a profissão, controlar os dirigentes e proceder a auto-organização rumo à transformação societária.

\section{Referências}

ATCON, Rudolph P. La universidad latinoamericana: clave para un enfoque conjunto del desarrollo coordinado social, económico y educativo em América Latina. Bogotá: Universidade Nacional de Colombia, 1961. Disponível em http://pt.scribd.com/doc/36270991/Rudolph-Atcon-La-Universidad-a-v-libro.

20 Sobre a iniciação científica no nível médio de ensino, ver Silveira (2015). 
BECKER, Gary S. The economic way of looking at life. The Nobel Foundation: Economic Sciences, 1992. Disponível em: https://www.nobelprize.org/prizes/economicsciences/1992/becker/biographical/, acesso em 20/04/2020.

BRASIL. Decreto $\mathbf{n}^{\circ} \mathbf{9 . 2 8 3}$, de 7 de fevereiro de 2018. Regulamenta a Lei $n^{\circ} 10.973$, de 2 de dezembro de 2004, a Lei $n^{\circ} 13.243$, de 11 de janeiro de 2016, o art. 24, § $3^{\circ}$, e o art. 32 , $\S 7^{\circ}$, da Lei $n^{\circ} 8.666$, de 21 de junho de 1993, o art. $1^{\circ}$ da Lei $n^{\circ} 8.010$, de 29 de março de 1990, e o art. $2^{\circ}$, caput, inciso I, alínea "g", da Lei n 8.032, de 12 de abril de 1990, e altera o Decreto $n^{\circ} 6.759$, de 5 de fevereiro de 2009, para estabelecer medidas de incentivo à inovação e à pesquisa científica e tecnológica no ambiente produtivo, com vistas à capacitação tecnológica, ao alcance da autonomia tecnológica e ao desenvolvimento do sistema produtivo nacional e regional. Brasília (DF): 2018. Disponível em: http://www.planalto.gov.br/ccivil 03/ Ato2015-2018/2018/Decreto/D9283.htm , acesso em 20/04/2020.

BRASIL. Decreto-Lei $\mathbf{n}^{\circ}$ 719, de 31 de julho de 1969. Cria o Fundo Nacional de Desenvolvimento Científico e Tecnológico e dá outras providências. Brasília (DF): 1969. Disponível em: https://www2.camara.leg.br/legin/fed/declei/1960-1969/decreto-lei-71931-julho-1969-362732-normaatualizada-pe.html , acesso em 20/04/2020.

BRASIL. Lei $\mathbf{n}^{\circ} \mathbf{1 0 . 9 7 3}$, de 2 de dezembro de 2004. Dispõe sobre incentivos à inovação e à pesquisa científica e tecnológica no ambiente produtivo e dá outras providências. Brasília (DF): 2004. Disponível em: http://www.planalto.gov.br/ccivil 03/ato20042006/2004/lei/l10.973.htm, acesso em 20/04/2020.

BRASIL. Lei $n^{\circ}$ 13.243, de 11 de janeiro de 2016. Dispõe sobre estímulos ao desenvolvimento científico, à pesquisa, à capacitação científica e tecnológica e à inovação e altera a Lei $n^{\circ}$ 10.973, de 2 de dezembro de 2004, a Lei $n^{\circ}$ 6.815, de 19 de agosto de 1980, a Lei $n^{\circ} 8.666$, de 21 de junho de 1993, a Lei $n^{\circ} 12.462$, de 4 de agosto de 2011, a Lei $n^{\circ}$ 8.745, de 9 de dezembro de 1993, a Lei $n^{\circ} 8.958$, de 20 de dezembro de 1994, a Lei $n^{\circ}$ 8.010, de 29 de março de 1990, a Lei n 8.032 , de 12 de abril de 1990, e a Lei $n^{\circ} 12.772$, de 28 de dezembro de 2012, nos termos da Emenda Constitucional n 85, de 26 de fevereiro de 2015. Brasília (DF): 2016. Disponível em http://www.planalto.gov.br/ccivil_03/Ato20152018/2016/Lei/L13243.htm, acesso em 20/04/2020.

BRASIL. Lei $\mathbf{n}^{\circ}$ 5.727, de 4 de novembro de 1971. Dispõe sobre o Primeiro Plano Nacional de Desenvolvimento (PND). 1972-1974. Brasília (DF): 1971. Disponível em: http://www.biblioteca.presidencia.gov.br/publicacoes-oficiais/catalogo/medici/i-pnd-

$\underline{72} 74$, acesso em 20/04/2020.

BRUM, Argemiro. O Desenvolvimento econômico brasileiro. Petrópolis, RJ: Editora Vozes, 1982.

CASANOVA, Pablo González. As novas ciências e as humanidades: da academia à Política. São Paulo: Boitempo, 2006.

CIPOLLA, Francisco Paulo. A inovação na teoria de Marx. In: PELAEZ, Victor; SZMRECSÁNYI, Tamás (Orgs.). Economia da inovação tecnológica. São Paulo: Hucitec: Ordem dos Economistas do Brasil, 2006.

DOS SANTOS, Theotonio. Revolução científico-técnica, divisão internacional do trabalho e sistema económico mundial. Cadernos ANGE: Vitória, 1994. 
DREIFUSS, René. A internacional capitalista. Estratégias e táticas do empresariado transnacional (1918- 1986). Rio de Janeiro: Espaço e Tempo, 1986.

DREIFUSS, René. Transformações: matrizes do século XXI. Petrópolis: RJ: Vozes, 2004.

FERNANDES, Florestan. A Ciência aplicada e a educação como fatores de mudança cultural provocada. São Paulo: S.M.P. E., 1959.

FERNANDES, Florestan. A formação política e o trabalho do professor. In: CATANI, Denice Bárbara et. al. (Orgs.). Universidade, escola e formação de professores. São Paulo: Brasiliense, 1986, pp. 13-37.

FREITAS, Luiz Carlos. Rumo ao politecnismo. São Paulo: Expressão Popular, 2013.

FRIGOTTO, Gaudêncio. A produtividade da escola improdutiva: um (re) exame das relações entre educação e estrutura econômico-social e capitalista. 7. ed. São Paulo: Cortez, 2001.

GRAMSCI, Antonio. Cadernos do cárcere. v.2. Os intelectuais e o princípio educativo. Jornalismo. 2.ed. Rio de Janeiro: Civilização Brasileira, 2001.

GRAMSCI, Antonio. Cadernos do cárcere. v.3. Maquiavel; Notas sobre o Estado e a política. 3.ed. Rio de Janeiro: Civilização Brasileira, 2007.

HARVEY, David. Condição pós-moderna. 14. ed. São Paulo: Edições Loyola, 2005.

IANNI, Otávio. Estado e planejamento econômico no Brasil. 6. Ed. Rio de Janeiro: Civilização Brasileira, 1996.

IANNI, Otávio. Imperialismo na América Latina. 2. ed. Rio de Janeiro: Civilização Brasileira, 1988.

LONGO, Waldimir Pirró; DERENUSSON, Maria Sylvia. FNDCT, 40 anos. Revista Brasileira de Inovação. Campinas: UNICAMP; FINEP, v. 8, no 2, 2009, pp. 515-533.

MARINI, Ruy Mauro. 3.ed. Subdesenvolvimento e revolução. Florianópolis: Insular, 2012. MARINI, Ruy Mauro. Dialética da dependência. Petrópolis, RJ: Vozes: Buenos Aires, Ar.: CLASO, 2000.

MARINI, Ruy Mauro. La acumulación capitalista mundial y el subimperialismo. Cuadernos Políticos. México: Ediciones Era, no 12, abr./jun., 1977. Disponível em: http://www.mariniescritos.unam.mx.

MARX, Karl. Elementos fundamentales para la Crítica de la economía política (Grundisse) 1857-1858, v. 2. 8. reimp. México: Siglo XXI Editores S.A., 2009.

MARX, Karl. O capital: crítica da economia política: livro I, v. I. 22. ed. Rio de Janeiro: Civilização Brasileira, 2004.

MARX, Karl. O capital: crítica da economia política: livro III: o processo global da produção capitalista. São Paulo: Boitempo, 2017.

MARX, Karl. Trabalho assalariado e Capital \& Salário, preço e lucro. São Paulo: Expressão Popular, 2006. 
MEDEIROS, João Leonardo. A economia diante do horror econômico: uma crítica ontológica dos surtos de altruísmo da ciência econômica. Niterói: EdUFF, 2013.

MÉSZÁROS, István. Para além do capital. 2 reimp. 1. ed. São Paulo: Boitempo, 2006.

MINISTÉRIO DA EDUCAÇÃO E CULTURA. Relatório da Equipe de Assessoria ao Planejamento do Ensino Superior (Acordo MEC-USAID). Brasília: MEC: EAPES, 1969. Disponível em: http://www.dominiopublico.gov.br/download/texto/me002109.pdf, acesso em 20/04/2020.

MINISTÉRIO DA EDUCAÇÃO. Departamento de Assuntos Universitários. Relatório Anual 1977. Brasília: MEC: DAU, 1978.

MINISTRO DA CIÊNCIA, TECNOLOGIA, INOVAÇÕES E COMUNICAÇÕES. Portaria MCTIC $\mathbf{n}^{\circ} \mathbf{1 . 1 2 2}$, de 19 de março de 2020. Define as prioridades, no âmbito do Ministério da Ciência, Tecnologia, Inovações e Comunicações (MCTIC), no que se refere a projetos de pesquisa, de desenvolvimento de tecnologias e inovações, para o período 2020 a 2023. Brasília (DF): 2020. Disponível em: https://www.mctic.gov.br/mctic/opencms/legislacao/portarias/Portaria MCTIC n 1122 de 19032020.html, acesso em 20/04/2020.

OLIVEIRA, Francisco. Crítica à razão dualista - O ornitorrinco. São Paulo: Boitempo, 2003.

SCHUMPETER, Joseph. Os economistas: Teoria do desenvolvimento econômico. Uma investigação sobre lucros, capital, crédito, juro e ciclo econômico. São Paulo: Nova Cultural, 1997.

SILVEIRA, Zuleide S. Concepção de educação tecnológica na reforma do ensino médio e técnico no governo FHC; resultado de um processo histórico. Revista Trabalho Necessário, ano 6, $n^{\circ}$ 6, 2008.

SILVEIRA, Zuleide S. Concepções de educação tecnológica na reforma da educação superior: finalidades, continuidades, e rupturas - estudo comparado Brasil e Portugal (1995-2010). Niterói: 2011. Tese (Doutorado em Educação) - Programa de Pós-Graduação em Educação, Universidade Federal Fluminense.

SILVEIRA, Zuleide S. Formação científica no nível médio: primeiras aproximações. Boletim Técnico do Senac. Rio de Janeiro, v. 41, n. 1, p. 36-57, jan./abr. 2015.

SIMONSEN, Mario Henrique; CAMPOS, Roberto de Oliveira. A nova economia brasileira. Rio de Janeiro. Livraria José Olympio Editora, 1974.

TEIXEIRA, Anísio. Educação e universidade. Rio de Janeiro: EdUFRJ, 1988.

VELHO, Léa. Modos de produção de conhecimento e inovação estado da arte e implicações para a Política Científica, Tecnológica e de Inovação - Nota Técnica. In: CGEE. Centro de Gestão e Estudos Estratégicos. Projeto nova geração de políticas de Ciência, Tecnologia e Inovação. Brasília, DF, 2006.

VICENZI, Letícia Braga. Educação como capital humano (uma análise crítica). Rio de Janeiro: Gráfica Borsói S.A., 1983. 


\title{
Informações sobre a autora:
}

\section{Zuleide S. Silveira}

Doutora em Educação pela Universidade Federal Fluminense (UFF), com doutoramento intercalar na Universidade de Lisboa. Atua como professora da Faculdade de Educação da UFF, onde integra o quadro docente do Programa de Pós-Graduação em Educação; Coordenadora do Grupo de Pesquisa Estado, Trabalho, Educação e Desenvolvimento: pensamento crítico latino-americano e tradutibilidade de Antonio Gramsci (GPETED/UFF); é Editora-Chefe da Movimento Revista de Educação. É membro do Fórum da Gestão do Ensino Superior nos Países e Regiões de Língua Portuguesa, com sede em Lisboa. ORCID iD: http://orcid.org/0000-0002-7855-2484. E-mail: zuleidesilveira@gmail.com

\author{
Submetido em: $\quad 20 / 04 / 2020$ \\ Aprovado em: $\quad 29 / 04 / 2020$
}

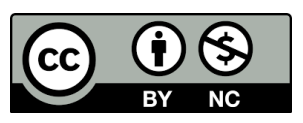

Esta obra está licenciada com uma Licença 